\title{
Random clinical trial to evaluate the effect of a multimodal intervention in hand hygiene in primary care in Madrid
}

\author{
A Cañada*, Carmen Martín, Sonia Soto, Juan Carlos Abánades, Miguel Salinero \\ From International Conference on Prevention \& Infection Control (ICPIC 2011) \\ Geneva, Switzerland. 29 June - 2 July 2011
}

\section{Introduction / objectives}

Objective was to evaluate the effectiveness of multimodal intervention, in primary health care professionals, to improve compliance with practice of hand hygiene, based on WHO's 5 moments.

\section{Methods}

Double blind, parallel group clinical trial with control group (CG), randomized by cluster. Performed at 21 primary health care centers, during 2009-2010, with 214 health professionals.

Hand hygiene compliance level was evaluated at the moment basal and six months after the intervention, by a single external observer. Professionals ignored in which activity they were being observed, previously signed an informed consent.

Variables:related to WHO's 5 moments and with professionals (profession, sex, type of contract and years of experience).

Multimodal intervention carried out with intervention group (IG), consisted of a theoretical-practical workshop in four sessions, providing the visiting room with hydroalcoholic solutions and reminder signs.

Statistical analysis: descriptive analysis, Student's t for independent samples, and the Mann-Whitney U or the Kruskal-Wallis test and multiple linear regression techniques have been utilized to analyze baseline compliance.

\section{Results}

Study was completed by 170 professionals: 84 (IG), 86 (CG), with no differences in the baseline characteristics. Professionals in the intervention group increased their level

Gerencia de Atención Primaria, Servico Madrileño de la Salud, Madrid, Spain of compliance for hand hygiene by 21.6 points (C195\% from 13.83 to 28.48), compared with the control group. Moment 1 showed the highest increase in improvement ( 9.5 points). The level of compliance basal was 8.1\% (CI95\% from 6.2 to 10.1). More than 20 years of job experience is significantly associated with very low levels of compliance.

\section{Conclusion}

Compliance with hand hygiene can be improved with a multimodal intervention, fundamentally training. It provides a valid methodology to other health centers.

\section{Disclosure of interest}

None declared.

Published: 29 June 2011

doi:10.1186/1753-6561-5-S6-P257

Cite this article as: Cañada et al.: Random clinical trial to evaluate the effect of a multimodal intervention in hand hygiene in primary care in Madrid. BMC Proceedings 2011 5(Suppl 6):P257.

Submit your next manuscript to BioMed Central and take full advantage of:

- Convenient online submission

- Thorough peer review

- No space constraints or color figure charges

- Immediate publication on acceptance

- Inclusion in PubMed, CAS, Scopus and Google Scholar

- Research which is freely available for redistribution 